\title{
DROGAS, PERFORMANCE E PSIQUIATRIZAÇÃO NA CONTEMPORANEIDADE
}

Joel Birman

\author{
Joel Birman \\ Psicanalista, \\ membro do \\ Espaço Brasileiro \\ de Estudos \\ Psicanalíticos e do \\ Espace Analytique; \\ professor titular \\ do Instituto de \\ Psicologia da UFRJ; \\ professor adjunto \\ do Instituto de \\ Medicina Social \\ da Uerj; diretor \\ de Estudos em \\ Letras e Ciências \\ Humanas, \\ Universidade Paris \\ VII; pesquisador \\ associado do \\ laboratório \\ Psicanálise, \\ Medicina e \\ Sociedade, \\ Universidade \\ Paris VII.
}

RESUMO: Pretende-se estabelecer as relações existentes entre o uso de drogas na atualidade e o imperativo da performance estabelecido socialmente, indicando que isso ocorre tanto com as drogas ilícitas quanto com as lícitas.

Palavras-chave: Drogas, performance, psiquiatrização.

ABSTRACT: Drugs, performance and psychiatrization in the contemporary world. The aiming of this paper is to establish the relationships between the use of drugs today and the performance in the social space, as well as showing that this process is reached through legal and illegal drugs.

Keywords: Drugs, performance, psychiatrization.

\section{PREÂMBULO}

A intenção primordial deste ensaio é a de estabelecer as relações existentes entre a utilização regular de drogas e a produção da performance na contemporaneidade, pelos indivíduos. É preciso dizer, antes de mais nada, que estas relações são múltiplas, de maneira a modularem formas de subjetivação (FOUCAULT, 1976) específicas, que é preciso colocar devidamente em evidência.

Contudo, é preciso dizer ainda, de forma preliminar, que por drogas não é compreendido aqui apenas aquelas ditas ilegais, que estão na base da produção e do desenvolvimento do narcotráfico, mas também as drogas ditas medicinais, prescritas como medicamentos, com a finalidade de regulação de diferentes paixões e de diversas perturbações psíquicas. Isso porque, se a ênfase colocada nas drogas ilegais já deu margem para múltiplas publicações, a inscrição dos psicofármacos no campo das drogas propriamente ditas, em contrapartida, não 
foi objeto de reflexão e de pesquisa como deveria. No que concerne a isso, as publicações são escassas, para não dizer inexistentes.

Ao enunciar tal pretensão, portanto, o tema deste ensaio se alarga bastante, pois o que estará em pauta não é apenas o binômio estabelecido entre os registros da droga e da performance, mas o trinômio tecido nas relações entre a droga, a performance e a medicalização da existência hoje. Além disso, é preciso enfatizar que uma das vias privilegiadas desta medicalização na atualidade se realiza pela mediação da psiquiatria. Com efeito, foi pela trilha da psiquiatrização da existência dos indivíduos, no Ocidente, que estas relações se estabeleceram, de maneira que a construção e a expansão do código de classificação de transtornos psíquicos (DSM), da Associação Americana de Psiquiatria, é o signo mais eloquente deste processo abrangente.

Enfim, o que se impõe neste ensaio é a construção de uma problemática (FOUCAULT, 1984, p.350-370; DELEUZE \& GUATTARI, 1980) específica, pela conjunção entre os diferentes registros da droga, da performance e psiquiatrização, pela qual se pretende enfatizar a produção de formas de subjetivação dos indivíduos na atualidade.

\section{DROGAS E GRAMÁTICAS}

Assim, não existe qualquer dúvida de que nas últimas décadas, no Ocidente, ocorreu não apenas um incremento ostensivo do uso de drogas ilegais, como a emergência e a oferta de novas modalidades de drogas aumentaram decisivamente na atualidade. No que se refere a isso, são as drogas sintéticas as que mais se disseminam e ganham a preferência dos usuários, pois são mais baratas e facilitam o seu consumo em diferentes segmentos sociais das populações.

Além disso, é preciso evocar ainda que a articulação estabelecida inicialmente entre o consumo de drogas e a experiência da compulsão nos indivíduos, como se esta fosse a condição concreta de possibilidade para a sustentação e o desenvolvimento da adição, se ampliou e se disseminou de maneira vertiginosa. O que se passou a formular nos últimos anos, é que a compulsão e a adição não se restringem mais ao campo das drogas, mas se disseminou para outros objetos, de forma que estas passaram a serem consideradas no seu uso como práticas compulsivas. Foi o que ocorreu não apenas com o álcool e o cigarro, mas com a comida, o computador, a internet, etc. (BIRMAN, 2012).

No que tange à relação estabelecida entre a compulsão e as adições é preciso considerar devidamente que, numa leitura psicanalítica, a compulsão é a tentativa desesperada realizada pelo sujeito para se desembaraçar e assim elaborar uma experiência da ordem do trauma. Portanto, seria uma experiência traumática o que estaria efetivamente subjacente no sujeito impelido às compulsões, de forma que 
a compulsão à repetição, descrita por Freud em Além do princípio do prazer (FREUD, 1920/1981), estaria na base desta experiência psíquica (BIRMAN, 2012).

No entanto, é preciso enunciar ainda que ocorreu uma transformação significativa no estilo (BIRMAN, 1996) de utilização de drogas no Ocidente, desde os anos 1980 e 90. Assim, nos anos 1950, 60 e 70, a utilização de drogas se inscrevia efetivamente num projeto existencial, ético e político de transformação do mundo. Assim, pela utilização de drogas os usuários buscavam a abertura das portas da percepção, isto é, a assunção de novos limiares sensoriais, para parodiar Huxley (1960), com vistas à transformação concreta do mundo. Portanto, neste contexto, o uso de drogas visava a antecipação de novos mundos possíveis, que seriam então freneticamente ritualizados pela experiência das drogas (BIRMAN, 1999, p.231-246).

Esta modalidade específica de uso de drogas retomava uma matriz constituída na primeira metade do século XIX (BIRMAN, 1999, p.231-246) no qual os poetas, os pintores e os artistas em geral se valiam das drogas para delinearem novos mundos, pela abertura de novos limiares sensoriais para a ocorrência da percepção. Seria em decorrência da abertura de outros mundos possíveis que a escrita poderia ser relançada em novos patamares, bem como a construção de outros espaços pictóricos, de forma que a modelagem desta matriz existencial se constituiu na tradição do romantismo, e Baudelaire foi um exemplo eloquente disso na história do imaginário literário, no Ocidente (BAUDELAIRE, 1966).

Contudo, nos anos 1950, 60 e 70, as aspirações de novos mundos possíveis não se restringiram apenas aos registros da literatura, da pintura e do teatro, mas se deslocaram para o mundo da música popular e da prática política, de maneira decisiva. Assim, não existiria mais então qualquer diferença entre as posições da arte, da vida, do sonho e da política, de forma que as manifestações sociais de maio de 1968, iniciadas em Paris e que se disseminaram em seguida pelo mundo, foram a ritualização coletiva mais eloquente desta experiência fundamental na recente tradição do Ocidente.

Porém, desde os anos 1980 e 90, ocorreu uma transformação radical na gramática do uso de drogas, pois estas passaram a ser utilizadas sem qualquer inscrição num projeto utópico de forjar outros mundos possíveis e se reduziram, assim, na sua abrangência existencial. Desde então o que passou a ficar em pauta para o sujeito seria o de suportar as agruras do mundo presente, por um lado, e o de incrementar a performance do sujeito nas demandas existentes na atualidade. Enfim, constituiu-se uma nova gramática na utilização de drogas, que se opunha nos menores detalhes da gramática existente no Ocidente, desde a primeira metade do século XIX (BIRMAN, 1999, p.247-266).

Se na gramática anterior de utilização de drogas pelo sujeito o que estava em pauta na sua utopia era a pretensão de encantamento do mundo, o que pas- 
sou a ficar em pauta desde os anos 1980 e 90 foi o desencantamento do mundo (BIRMAN, 1999, p.231-246). Portanto, no mundo habitado pela figura de “Dionísio desencantado”, o que está em pauta é o imperativo da performance e é isso o que delineia a nova gramática da utilização de drogas no Ocidente. Em decorrência disso, outras modalidades de subjetivação foram engendradas, para modelarem o imperativo crucial da performance pelo sujeito.

\section{PERFORMANCE, ATIVIDADE E DOMÍNIO}

É evidente que, do ponto de vista psicanalítico, esta promoção permanente da performance se funda, na metapsicologia, naquilo que Freud, desde os Três ensaios sobre a teoria da sexualidade, denominou de pulsão de domínio (FREUD, 1905/1962, p.54-66). Nesta, o sujeito buscaria não apenas controlar o objeto em busca de realizar a experiência da satisfação, sem considerar nunca o que isso possa implicar de inquietação para o outro, em termos de dor e de sofrimento, mas quer impor o seu poder sobre este de forma cruel. É o sadismo, portanto, que está aqui em pauta de maneira crua, no poder que o sujeito quer exercer ativamente sobre o outro.

Ao lado disso, a dita performance do sujeito se fundaria numa atividade permanente e insistente do sujeito, como se qualquer posição de passividade face ao outro e ao mundo fosse uma marca eminentemente negativa, e devesse então ser afastada, custe o que custar. Nesta atividade ininterrupta do sujeito o que se enuncia efetivamente em ato é o privilégio absoluto assumido pelo gozo fálico na atualidade, de maneira que qualquer marca de passividade no sujeito colocaria em evidência uma feminilidade inaceitável e que por isso mesmo deveria ser eminentemente repudiada por aquele, pelo relançamento permanente da afirmação fálica e sem trégua.

É preciso sublinhar ainda que, nesta articulação estabelecida entre os registros da pulsão de domínio, do sadismo, da atividade e do gozo fálico, o que está em pauta é a afirmação permanente da masculinidade, transformado que foi este signo em bem supremo hoje face a uma feminilidade a ser sempre repudiada pelo sujeito. O que implica dizer que a virilidade como valor moral está em alta na contemporaneidade, tanto entre os homens quanto entre as mulheres.

No que tange esta indistinção de gêneros, no que concerne à virilidade performática, a disseminação da violência e da crueldade é um dos efeitos mais eloquentes desta modalidade de subjetivação. De fato, se a violência e a crueldade se incrementam hoje de maneira evidente, como atestam as pesquisas sociológicas em nível internacional, isso se deve à ênfase assumida pela virilidade e pela performance nas formas de subjetivação no mundo contemporâneo (BIRMAN, 2009, p.25-40; 2012). 
É esta forma de subjetivação, que se construiu e se faz então patente na cultura da performance, que se espraia agora, se evidenciando na nova gramática de uso de drogas ilícitas. Porém, esta questão não se restringe a esta modalidade do uso de drogas, mas se faz igualmente presente no campo das drogas prescritas pela medicina.

\section{INFLAÇÃO DOS PSICOTRÓPICOS}

Entretanto, não se sublinhou devidamente que este incremento na utilização de drogas ilícitas no Ocidente — que foi o corolário para a constituição de outra gramática na utilização de drogas e para a construção de novas modalidades de subjetivação - foi acompanhado de perto pela transformação na utilização de drogas prescritas pela psiquiatria, com finalidade terapêutica. Decerto, a revolução no campo da psicofarmacologia está na base desta disseminação das drogas ditas 'medicinais'.

Assim, se nas últimas décadas o tráfico das drogas ilícitas cresceu enormemente no mundo, não existindo qualquer dúvida em relação a isso, a comercialização e a utilização de psicotrópicos atingiram igualmente um crescimento exponencial, de forma que este se transformou em uma das novas mercadorias mais valorizadas no mundo contemporâneo. Se a economia do narcotráfico se multiplicou e adquiriu ganhos incalculáveis, a indústria farmacêutica expandiu bastante os seus lucros, e a acumulação de riqueza por ela possibilitada se empreendeu de maneira exponencial (JACOBSEN, 2013, p.298-322).

Porém, se a primeira expansão de drogas é o foco insistente da crítica da mídia em escala internacional e está no centro da política de Estado dos países hegemônicos, em contrapartida, não se fala quase nada desta segunda expansão, de forma significativa. Assim, este silêncio eloquente sobre esta segunda expansão maciça de drogas se justificaria então pelas finalidades terapêuticas que regulariam o seu uso, tendo, pois, uma legitimidade efetiva, pois estas se voltariam para a promoção do bem e não do mal nas populações, contrariamente às drogas ilícitas. Tudo se passa então como se isso não colocasse problema e não fosse em si mesmo um problema, mas um serviço para a expansão da saúde e do bem-estar, promovendo então a melhoria ostensiva das perturbações psíquicas nas populações.

Além disso, não se falou que a expansão e a disseminação efetiva do narcotráfico, em escala internacional, tiveram como uma das suas condições concretas de possibilidade a construção e a banalização de dispositivos tecnológicos oriundos do discurso da ciência, promovidos que foram pela farmacologia em geral e a psicofarmacologia em particular. Assim, graças às possibilidades entreabertas por tais dispositivos tecnológicos, foi possível a instalação de laboratórios químicos 
de produção de drogas ilícitas em regiões inóspitas, como a Floresta Amazônica e o Afeganistão, por um lado, e promover novas misturas que incrementaram fartamente o ganho econômico dos narcotraficantes, pelo outro. Da mesma forma, a produção de novas drogas sintéticas não teria sido possível sem a incorporação ativa pelo narcotráfico dos novos dispositivos tecnológicos promovidos pelo discurso da ciência (BIRMAN, 1999, p.247-266).

Entretanto, pela produção dos processos de subjetivação que foram assim promovidos, pelo uso legal dos psicofármacos, é preciso destacar ainda que se produziu uma diminuição ostensiva nos sujeitos dos limiares de dor e de angústia, de maneira que hoje o nosso limiar para suportar tais paixões diminuiu vertiginosamente, como efeito direto da regulação destas pelos psicofármacos (BIRMAN, 2012).

Portanto, é o imperativo insofismável de psiquiatrização da existência humana, nos seus menores detalhes, o que está em pauta aqui de maneira eloquente, de fato e de direito, nesta expansão da performance, que tem como contraponto a regulação ostensiva das experiências da dor e da angústia. Seria isso, enfim, o que estaria de fato em pauta como o que legitima e cauciona a inflação do consumo de psicotrópicos pelos indivíduos hoje.

\section{DESCONSTRUÇÃO DO ESPAÇO PÚBLICO E INFLAÇÃO DA INTIMIDADE}

Porém, para complexificar ainda mais a leitura aqui proposta, é preciso enfatizar que a diminuição dos limiares subjetivos para a dor e a angústia, como corolários para o imperativo da performance do sujeito, se inscreve num novo mundo de horizontes sociais que devem ser colocados devidamente em evidência. Os discursos das ciências sociais procuraram teorizar sobre isso, ao destacar, nas coordenadas constitutivas do espaço social, que uma inflexão decisiva se realizou nas últimas décadas, qual seja: a desconstrução progressiva do espaço público e a expansão correlata do espaço privado. Se, por esta inflexão, a intimidade na existência dos sujeitos foi incrementada de maneira eloquente a expensas de suas inscrições no espaço público, como ocorria na modernidade, o narcisismo como marca fundamental nas formas de subjetivação foi o seu desdobramento efetivo e inevitável.

Assim, numa obra que foi publicada em 1976, Sennett deu o tom inicial que marcou este grande debate. Já em O declínio do homem público, com efeito, Sennett (1980) formulou como o campo do espaço público foi se esvaziando pouco a pouco e teve como contraponto a inflação do espaço privado na existência dos indivíduos. A contrapartida disso foi o incremento ostensivo das "tiranias da intimidade" - que é, aliás, o subtítulo da obra em questão. Dessa maneira, o espaço social constituído progressivamente desde a aurora da modernidade, no final do século XVIII, e que foi ainda enfatizado nas suas coordenadas fundamen- 
tais na modernidade avançada — centrado na importância conferida no espaço público e à figura do cidadão — , começou a ser descontruído, invertendo as suas linhas de força fundamentais, pois seria pela ênfase nos registros do espaço privado e da intimidade que o espaço social estaria sendo reconfigurado hoje, de maneira decisiva (SENNETT, 1980).

Em outra obra, publicada em 1979, Lasch (2006) destacou como o movimento das linhas de força em direção ao espaço privado e à intimidade foi constitutivo do que denominou de cultura do narcisismo, que é, aliás, o título do seu livro. De fato, nesta inflexão em direção aos registros do privado e do íntimo, as formas de subjetivação foram decididamente reconfigurados, marcadas que seriam pelo narcisismo.

Em 1998, Sennett retomou este debate por outro ângulo de análise, mas que seria complementar ao que delineara na obra inicial, pois se voltou agora para as novas condições do campo do trabalho na atualidade. Enunciou assim, que estas novas coordenadas instituídas no mercado de trabalho no novo capitalismo - caracterizado que foi pela desconstrução do espaço público e a expansão do espaço privado na existência dos indivíduos - , teria promovido ostensivamente a corrosão do caráter dos trabalhadores (SENNETT, 1999), na medida em que estes perderiam as linhas de força básicas de sua constituição simbólica e ficariam à deriva nas oscilações existentes nesse mesmo mercado (idem). Em decorrência disso, as categorias do espaço e do tempo, que seriam constitutivas do sujeito, não funcionariam da mesma maneira na modernidade e na pós-modernidade. Enfim, seria justamente por isso que seria promovida a dita desconstrução do caráter nos indivíduos na atualidade.

Foi ainda no início deste contexto histórico, em 1967, que Debord enunciara que o que caracterizava a modernidade avançada seria a constituição da sociedade do espetáculo, na qual os registros do ser e do parecer deixariam de ser opostos e diferenciados, pois estariam sempre misturados nos simulacros que forjariam as subjetividades. Com efeito, a cena social estaria sendo transformada numa cena teatral, tendo suas coordenadas orientadas pelo imperativo da performance e pela disseminação de simulacros que as modelariam.

Em Sociedade de risco, obra publicada em 1986, Beck formulou como o espaço social na atualidade seria marcado pelo imperativo do risco, que incidiria ao mesmo tempo nas subjetividades e nos laços sociais, de forma a relançar em outras bases as linhas de força estabelecidas na aurora da modernidade e na modernidade avançada (BECK, 1986/2010). Estaríamos constituindo assim outra modernidade, na qual o imperativo do risco estaria então permanentemente presente.

Em 1983, o sociólogo francês Robert Castel formulara que, no espaço social contemporâneo, o que estaria sempre em pauta era a gestão dos riscos — aliás, o título de sua obra (CASTEL, 1983). Pode-se daí depreender como a leitura de 
Beck sobre o espaço social na atualidade se conjuga intimamente com o que foi formulado um pouco antes por Castel, mas no mesmo contexto histórico. Enfim, seria sempre o risco o que estaria em pauta desde então.

Pode-se dizer assim que, se a iminência do risco marca as subjetividades em nossos tempos, isso se deve ao imperativo da performance que se impõe aos indivíduos no espaço social. Existiria então um risco permanente no imperativo da performance, fundado na desconstrução do espaço público e na inflação correlata do espaço privado, de forma que a tirania promovida na intimidade se desdobraria na cultura do narcisismo, o que promoveria a corrosão do caráter do sujeito.

\section{NEOLIBERALISMO E MAL-ESTAR}

Estas transformações sociológicas acima destacadas, que marcaram as descontinuidades existentes entre o espaço social na modernidade e na pós-modernidade, em torno de certas dimensões fundamentais - dentre as quais a desconstrução do espaço público e a expansão do espaço privado - , conduziram à performance e à sociedade do espetáculo, por um lado, e à emergência da sociedade de risco, pelo outro. Elas remetem aos novos limiares do processo de globalização da economia internacional e à constituição do neoliberalismo. Contudo, é importante destacar que este não é apenas uma modalidade de gestão da economia, mas que implica igualmente uma dimensão fundamental no campo da política (BORDIEU, 2000), que se evidencia pela construção do Estado neoliberal (BORDIEU, 1989-1992/2012; WACQUANT, 2009).

Desta maneira, o Estado neoliberal foi a contrapartida do Estado de bem-estar social estabelecido no Pós-Guerra, no qual o Estado realizava a mediação no espaço social e no campo da economia, no que tange à produção e à circulação de riquezas. Porém, desde o final dos anos 1970 a proposição do Estado mínimo se impôs ao Estado do bem-estar social, deixando à economia toda a liberdade para a sua expansão, que passou então a comandar o funcionamento efetivo dos diferentes Estados-nação. Estes perderam então o poder de realizar decisões fundamentais no que tange às suas populações, ficando à mercê de decisões tomadas alhures pelas empresas transnacionais. Vale dizer, com a constituição do Estado mínimo o poder soberano dos diversos Estados foram restringidos, em nome do poder assumido pela economia e pelo mercado. Com isso, enfim, a política foi esvaziada em nome da gestão e a governança passou a regular assim as práticas do Estado neoliberal.

É nesta perspectiva que se pode dizer que na pós-modernidade a sociedade, tal como foi concebida na aurora da modernidade e que tinha na figura do cidadão e na soberania popular as suas marcas fundamentais, entrou em processo ostensivo 
de desconstrução e foi substituída pelo mercado (REVAULT D'ALLONES, 2010; BROWN, 2007). Com isso, os cidadãos perderam direitos fundamentais, na medida em que o que se impôs foi a figura do consumidor como agente crucial do mercado. Tal processo estaria subjacente na desconstrução do espaço público e na inflação do espaço privado, com a construção da tirania da intimidade, segundo Sennett.

Estas transformações evidenciam, de maneira eloquente, que o neoliberalismo vigente hoje não foi a simples retomada das coordenadas presentes no liberalismo existente no século XIX, mas implicou rupturas cruciais em relação a este. Assim, no liberalismo clássico o Estado regulava parcialmente o funcionamento da economia e não deixava esta se impor na sociedade de maneira autônoma e imperativa, por um lado, e mesmo tomava ativamente para si algumas regiões privilegiadas do espaço social, pelo outro. Contudo, com o neoliberalismo, um conjunto de práticas sociais que estavam sob a regulação do Estado, passou a ser transformado em mercadoria e se transformou em ativos do mercado, como a educação, a saúde, a ciência, a arte e os saberes em geral.

Assim, a sociedade foi transformada num mercado, de forma que a figura do cidadão foi transformada na do consumidor. Por conta disso, o risco se impôs no espaço social de maneira generalizada, constituindo-se então a sociedade de risco. Vale dizer, se a performance como forma de subjetivação passou a ser um imperativo para os indivíduos neste contexto social, isso se deve ao fato que de cada indivíduo foi transformado numa microempresa e num empresário de si mesmo, em todos os campos das práticas sociais, como nos disse Foucault em Nascimento da biopolítica (FOUCAULT, 2004).

Em nome da produtividade e da rentabilidade da economia, o desemprego foi incrementado em níveis vertiginosos. Dentre os desempregados se destacam os jovens que passaram a se inserir tardiamente no mercado de trabalho, e os trabalhadores na faixa etária dos 50 anos, que foram demitidos e substituídos por jovens trabalhadores, que custavam mais barato como mão de obra. Em decorrência disso, a rivalidade social existente entre os trabalhadores se incrementou bastante, em nome da disputa pelos postos de trabalhos que se reduziram (BIRMAN, 2012, p.52-84). Pode-se daí depreender, inicialmente, como a performance dos indivíduos se impôs como critério para a manutenção dos postos de trabalho, por um lado, assim como os processos de avaliação das práticas sociais se disseminaram, incidindo em todos os registros sociais (BIRMAN, 2010, p.217-244).

O desdobramento mais importante deste processo abrangente foi o incremento vertiginoso do mal-estar social e psíquico, para retomarmos o conceito enunciado por Freud em Mal-estar na civilização (FREUD, 1930/1971). Com a disseminação do mal-estar, nos segmentos pobres e médios das populações, que foram restringidos na oferta de trabalho e nos seus direitos sociais, a angústia e 
a perda da estima de si se incrementaram, em decorrência da mácula que atingiu a identidade social destas populações. O que orientou este processo, no registro das formas de subjetivação, foi a disseminação da vergonha como paixão, naqueles segmentos sociais.

Do ponto de vista psicanalítico, o que está aqui em pauta é um processo de desnarcisação dos indivíduos, resultante da mácula da vergonha que incidiu violentamente sobre as suas identidades sociais. Seria isso que promoveria a perda significativa da estima de si destes indivíduos. Em consequência, o masoquismo se espraiou nestas individualidades, como marca eloquente deste processo crucial que promoveu a perda da autoestima destas.

Foi este campo do mal-estar, assim configurado, que se transformou na condição concreta de possibilidade para promover de forma precisa a psiquiatrização das individualidades em nossos dias. O que esta pretende é a regulação ostensiva do campo do mal-estar, para impedir que este seja transformado em agressividade e em violência pelos sujeitos, na medida em que as instâncias institucionais de poder não reconhecem a legitimidade das demandas políticas daqueles segmentos sociais, destituídos que foram de quase tudo.

Em ensaio publicado em 1948, intitulado "A agressividade em psicanálise", Lacan formulou que, por um lado, a agressividade implica necessariamente o registro do sujeito e não pode ser pensado no registro estrito do comportamento, e, por outro, a agressividade é promovida pelo sujeito quando este não é reconhecido pela legitimidade de suas demandas (LACAN, 1948/1966, p.82-102).

Portanto, retomando a hipótese de pesquisa, pode-se enunciar que o que o processo de psiquiatrização pretende realizar, na contemporaneidade, é a regulação do dito mal-estar, para impedir que este se enuncie como agressividade e violência.

Porém, quando esta regulação falha, o que se impõe de fato é a criminalização e a judicialização da agressividade e da violência, como forma de regulação do mal-estar social. Assim, é preciso evocar que existe um consenso entre os autores de que ocorreu um incremento ostensivo do encarceramento no Ocidente, nos tempos do neoliberalismo (WACQUANT, 2009). Além disso, esta inflação significativa do sistema prisional se empreendeu sem que houvesse aumento de homicídios, como nos disse Wacquant (2009), indicando, pois, que novas categorias de criminalidade foram forjadas pelo Direito Penal para realizar esta regulação, tendo como contexto social básico a destituição dos direitos dos cidadãos no neoliberalismo (BIRMAN, 2012).

Portanto, é pela via preferencial da psiquiatrização do mal-estar que os indivíduos são regulados hoje. É o que se verá em seguida. 


\section{NATURALISMO, NEUROCIÊNCIA E COGNITIVISMO}

O processo de psiquiatrização do mal-estar se fundou nos discursos da neurobiologia e da psicofarmacologia, por um lado, e na expansão da psicologia cognitiva, pelo outro. O que promoveu a conjunção destes diferentes discursos teóricos foi a leitura que passaram a realizar da subjetividade, na qual esta foi esvaziada do registro do sujeito e a ênfase foi colocada fundamentalmente no registro de comportamento. Portanto, as dimensões simbólica e histórica do sujeito foram silenciadas em nome do investimento promovido na dimensão do comportamento. Enfim, foi por esta ênfase e investimento no registro do comportamento que a psiquiatria se tornou autônoma da psicanálise, se transformando assim em psiquiatria biológica, sustentada que foi nos discursos das neurociências e no cognitivismo.

Assim, a exceção e a diferença da condição humana no registro estrito da natureza, centrada que eram nos registros da linguagem e nos códigos simbólicos, foram colocadas em suspenso, em nome do imperativo da naturalização daquela condição específica. Foi por este viés que a singularidade do sujeito foi eclipsada, pelo investimento correlato do registro do comportamento.

Estas coordenadas epistemológicas, construídas no registro do saber, se condensaram na organização das diferentes versões do DSM, forjadas pela Associação Americana de Psiquiatria, desde os anos 1950. Quais são as marcas fundamentais constitutivas do DSM?

A primeira característica importante do DSM, de sua versão inicial em 1952 à última versão em 2013, foi o despojamento progressivo do registro do sujeito, o que teve como contrapartida o incremento do registro do comportamento. Neste contexto, as referências ao discurso psicanalítico foram pouco a pouco silenciadas e tiveram como contraponto a inflação das categorias oriundas das neurociências e do cognitivismo.

A segunda característica crucial, nas diferentes versões do DSM, foi o incremento progressivo do número de categorias nosográficas, de forma que as particularidades comportamentais foram sendo cada vez mais colocadas em evidência, de maneira detalhada. De fato, se o DSM-I forjado em 1952 contava com 106 categorias diagnósticas, o DSM-III de 1980 contava já com 265 categorias e o DSM-IV de 1994 contava com nada menos que 297 categorias diagnósticas, o DSM-V forjado em 2013 conta com mais de 400 categorias diagnósticas.

No DSM-V, outras categorias diagnósticas foram incluídas, como a "síndrome de risco de psicose”, a “depressão nervosa”, a "perturbação neurocognitiva menor", a "ingestão alimentar excessiva”, a "perturbação da desregulação de humor com disforia” e a "perturbação da acumulação", que afetaria os indivíduos que não conseguem se desembaraçar de coisas e dos objetos. Pode-se depreender facilmente disso não apenas a heterogeneidade destas novas categorias nosográficas, 
como a sua particularização crescente para registros inusitados da experiência psíquica, como a "perturbação de acumulação”.

A terceira característica importante, nas novas versões de DSM, é que a construção das categorias diagnósticas se realizou pela conjugação interna de três instâncias institucionais que convergem para o mesmo objetivo: os laboratórios de pesquisa avançada em psiquiatria, as instâncias governamentais de saúde do governo norte-americano e os laboratórios farmacêuticos. Portanto, o que estava e continua ainda em pauta na construção do DSM foi a conjugação íntima entre os registros do saber, do mercado e do poder. Além disso, costumam ser os mesmos indivíduos os que se inscrevem nestes diferentes registros para a confecção das novas versões do DSM. Enfim, esta conjugação evidencia como a pesquisa psiquiátrica está diretamente ligada ao imperativo econômico do marcado e ao imperativo do poder governamental.

A quarta característica importante do DSM, nas suas diversas versões, foi a internacionalização efetiva do código de classificação diagnóstica. Se este foi forjado de início pela Associação Americana de Psiquiatria, para ter validade no território norte-americano, este código foi sendo incorporado progressivamente em outros países, pela mediação da Organização Mundial de Saúde e da Associação Internacional de Psiquiatria, as quais legitimaram o DSM. Contudo, pode-se evidenciar com facilidade, nesta internacionalização do DSM, que o que está em pauta primordialmente é o imperativo de mercado dos laboratórios farmacêuticos, que querem implantar seus produtos em escala internacional, pela justificativa supostamente científica conferida pelo discurso psiquiátrico de se ter a mesma categorização psiquiátrica em escala global.

Porém, se estas características delineiam o solo e balizam as marcas formais do DSM, é preciso dar agora outro passo, para que se possam examinar as características do sistema em termos de seus procedimentos metodológicos e epistemológicos. É o que veremos em seguida.

\section{PSIQUIATRIZAÇÃO DA NORMALIDADE}

A construção das categorias diagnósticas no DSM se funda na posição estratégica atribuída à categoria de síndrome no lugar da categoria de enfermidade, no discurso da medicina. Assim, a síndrome se configura pela articulação existente entre diferentes sintomas e sinais, delineando um quadro simplesmente funcional de uma dada perturbação sintomática, na qual a categoria de espaço predomina e na qual a categoria de tempo tende ao desaparecimento. Em decorrência disso, as categorias de etiologia e de causalidade de uma dada perturbação somática se relativizam e ficam colocadas num segundo plano, de forma que a categoria de história desaparece do discurso da medicina clínica. Portanto, todas estas características, 
que foram já silenciadas no discurso da medicina clínica na atualidade, existiam quando neste discurso dominava a categoria de enfermidade.

Esta transformação fundamental no discurso da medicina começou a ocorrer desde os anos 1960, norteando o discurso da medicina em outras direções teóricas (BIRMAN, 1999). Foi este novo modelo de descrição clínica, presente na medicina somática, o incorporado pelo discurso psiquiátrico desde os anos 60, de maneira progressiva. Nesta perspectiva, as descrições cada vez mais particulares e específicas presentes nos discursos psiquiátricos e transpostos na construção do DSM são fundadas na categoria de síndrome e não na de enfermidade.

Além disso, no novo discurso da medicina somática, a cada síndrome funcional e especificamente configurada, foi associado um projeto terapêutico de maneira a articular a categoria de síndrome com a proposição de um tratamento específico. No que tange ao novo discurso psiquiátrico, o mesmo processo foi repetido e incorporado, de forma que a cada síndrome configurada corresponde um dado psicofármaco, que seria em princípio capaz de regulá-la terapeuticamente. Portanto, no DSM, a cada categoria nosográfica corresponde um dado psicofármaco, que seria passível de aboli-la e de regulá-la.

Assim, a inclusão de um novo sintoma ou sinal numa síndrome já descrita no discurso psiquiátrico o mesmo processo será repetido e incorporado, na medida em que um novo psicofármaco será proposto para a regulação da nova síndrome. Desse modo, a inclusão de um novo sintoma e sinal numa síndrome já descrita implica a narrativa de outra síndrome, que implicará outros medicamentos capazes de regulá-la. Com efeito, a articulação do sintoma 'ansiedade’ na categoria diagnóstica de depressão implicou outro medicamento específico para a nova síndrome, que não seria o mesmo oferecido para a depressão pura. Da mesma forma, a articulação do sintoma 'dor’ na síndrome da depressão constituiria a fibromialgia, e implicou outra síndrome e outro medicamento para regular tal modalidade de depressão.

Entretanto, um terceiro processo estaria em pauta, além dos anteriores. Assim, neste particular a lógica que nortearia o processo pretende realizar a psiquiatrização daquilo que até então era considerado normal. Assim, se a dor e a tristeza sempre marcaram a tensão pré-menstrual, isso foi transformado, na atualidade, numa síndrome específica, que se fez pela psiquiatrização da normalidade. Da mesma forma, a tristeza que sempre existiu na experiência humana foi transformada em matéria-prima das depressões, que se transformaram então numa epidemia, psiquiatricamente induzida, nos anos 1980. Enfim, as variações de humor que sempre marcaram a existência humana foi recentemente psiquiatrizada, para a caracterização da bipolaridade como sendo a nova síndrome, desde o ano 2000, a que se deve medicar com psicofármacos diferentes dos que eram utilizados para a depressão. 
Dos anos 1960 até hoje, a psiquiatria biológica se centrou em três grandes humores e paixões humanas, para regulá-las com os psicofármacos, sem considerar aqui os neurolépticos usados para as psicoses. Os ditos humores e paixões são a angústia (1960-1980), a depressão (1980-2000) e a variação de humor (desde 2000). Porém, foram as razões de mercado as que conduziram às mudanças nas ênfases dadas a estas paixões e humores, e não as razões de ordem científica. De fato, se foi a consideração de que os ansiolíticos provocavam dependência o que conduziu à epidemia da depressão nos anos 1980, pela oferta de novas moléculas provocados pela indústria farmacêutica de então, o deslocamento da ênfase na depressão para a bipolaridade implicou a entrada do Prozac para o domínio público e o laboratório que o produzia investiu todas as suas fichas na promoção de moléculas voltadas para a regulação farmacológica da bipolaridade (JACOBSEN, 2013, p.298-323).

Foi nesta especificidade conferida para a síndrome, a que se articularia um medicamento psicofarmacológico determinado, que a performance como imperativo ideal a ser promovida no sujeito pelo discurso psiquiátrico se disseminou na contemporaneidade. Não está em pauta aqui o desenvolvimento científico, como seria o caso na relação estabelecida entre infecção e antibiótico na medicina somática (JACOBSEN, 2013, p.298-323), mas algo que visa à promoção da performance do sujeito, pela psiquiatrização ostensiva da normalidade.

Enfim, é este o horizonte da psiquiatria hoje, que psiquiatriza os indivíduos normais para torná-los performáticos, para enfrentar então os desafios colocados pela sociedade de risco da atualidade.

Recebido 29/11/2013. Aprovado em 20/12/2013.

\section{REFERÊNCIĀS}

BAUDELAIRE, C. (1966). Les paradis artificiels. Paris: Flammarion.

BAUMAN, Z. (1997). Post-modernity and its Discontents. Cambridge: Polity Press.

BECK, U. (1986/2010). Sociedade de risco. Rumo a uma outra modernidade. São Paulo: 34.

BIRMAN, J. (1996). Por uma estilística da existência. São Paulo: 34.

(1999). “Dionísios desencantado”, in Mal-estar na atualidade, Rio de Janeiro: Civilização Brasileira.

(1999). “La psychopathologie dans La post-modernité. Les alchimies dans le malaise de l'actualité”, in Psychologie Clinique, n.7. Paris: L’Harmattan.

(1999) “Que droga!!!”, in O mal-estar na atualidade. Rio de Janeiro: Civilização Brasileira, p.247-266.

(2009). "Juventude e condição adolescente na contempora- 
neidade: uma leitura da sociedade brasileira de hoje". In: BOCAYUVA, H., NUNES, S. A. Juventudes, subjetivações e violências. Rio de Janeiro: Contra-Capa.

(2010). L’Eclipse du sujet et de la singularité dans le discours de l'évaluation. Cahiers Internationaux de Sociologie, v.LXXVIII/ LXXIX. Paris: PUF. (2012). O sujeito na contemporaneidade. Rio de Janeiro: Civilização Brasileira.

(2012). “Adolescence sans fin? Péripéties du sujet dans un monde post-oedipien”, in MARTY, F.; CARDOSO, M. R. (Orgs.) France-Brésil: regards croisés. Paris: Press.

(2012). "Responsabilidade moral e criminalização na formação social neoliberal”, in MALAGUTI, Batista, V. (Org.). Loic Wacquant e a questão penal no capitalismo neoliberal. Rio de Janeiro: Revan.

BOURDIEU, P. (2000). Les structures sociales de l'economie. Paris: Seuil. . (2012). Sur l’État. Cours au Collège de France 1989-1992. Paris: Seuil.

BROWN, W. (2007). Les habits neufs de la politique mondiale. Paris: Les Prairies Ordinaires.

CASTEL, R. (1983). La gestion des risques. Paris: Minuit.

DÉBORD, G. (1992). La société du spectacle. Paris: Gallimard.

DELEUZE, G. \& GUATTARI, F. (1980). Capitalisme et schizophrenie. V.II. Mille Plateaux. Paris: Minuit.

FOUCAULT, M. (1976). La volonté de savoir. Paris: Gallimard. (1984). "Qu'est-ce que les lumières?”, Dits et écrits. V.IV. (2004). Naissance de la biopolitique. Paris: Gallimard/Seuil/EHESS.

FREUD, S. (1905/1962). Trois essais sur la théorie de la sexualité. Paris: Gallimard. (1920/1981). “Au-delà du principe de plaisir”, in Essais de psychanalyse. Paris: Payot.

(1930/1971) Malaise dans la civilisation. Paris: PUF.

HUXLEY, A. (1960). As portas da percepção, o céu e o inferno. Rio de Janeiro: Civilização Brasileira.

JACOBSEN, M.B. (2013). "Psycho pharmarketing", in La fabrique des folies. Paris: Sciences Humaines.

LACAN, J. (1948/1966). “L’agressivité en psychanalyse”, in Écrits. Paris: Seuil.

LASCH, C. (2006). La culture du narcissisme. La vie américaine à un âge de déclin des esperances. Paris: Flammarion.

ReVAult, D’AllonNes, M. (2010) Pourquoi nous n’aimons pas la démocratie. Paris: Seuil.

SENNETT, R. (1999). A corrosão do caráter. Rio de Janeiro : Record. (1980). O declínio do espaço público. As tiranias da intimidade. São Paulo: Cia das Letras.

WACQUANT, L. (2009). Punishing the Poor. The Neoliberal Gouvernement of Social Insecurity. Durham/Londres: Duke University Press.

Joel Birman

joelbirman@uol.com.br 
